\title{
La razón y el lenguaje, principios para entender la regeneración desde la lengua: Miguel Antonio Caro*
}

\author{
Diana Paola Guzmán **
}

\begin{abstract}
RESUMEN
Recibido: 3 de marzo de 2014

El presente trabajo intenta reflexionar y proponer el siglo XIX

Evaluado: 14 de abril de 2014 como un sistema de representación, en donde la actividad retóAceptado: 10 de mayo de 2014 rica lideraba el escenario político, el histórico y el social. Por tal motivo, estos sistemas enunciativos exponen, de manera clara y radical, una suerte de regímenes de representación, que evidenciaban, no sólo a través de la praxis del discurso sino también de su estudio y normatización, enfrentamientos en donde el sistema de jerarquización de la palabra, jugaba un papel fundamental de estudio y comprensión de la lengua como elemento de poder e identidad.
\end{abstract}

Palabras clave: regeneración, gramática, escritura, lenguaje, proposición.

Este texto es resultado de los procesos de investigación que pertenecen a la línea de análisis del discurso, adscrita al grupo Mente, lenguaje y sociedad del Departamento de Humanidades (clasificación A1 en Colciencias), Universidad Jorge Tadeo Lozano. Cómo citar este artículo: Guzmán, D. (2014). La razón y el lenguaje, principios para entender la Regeneración desde la lengua: Miguel Antonio Caro. Hallazgos, 11 (22), pp.19-40.

** Doctora en Literatura de la Universidad de Antioquia. Profesora titular del Departamento de Humanidades, Universidad Jorge Tadeo Lozano (Colombia). E-mail: dianap.guzmanm@utadeo.edu.co 


\title{
The reason and language, principles to understand the Regeneration from the language: Miguel Antonio Caro
}

\begin{abstract}
The present work attempts to reflect and propose the nineteenth century as a system of representation where the activity rhetoric led the political scenario, the historical and the social. For this reason, these systems enunciative exposed, so clear and radical, a sort of representation schemes that representationally, not only through the praxis of the speech but also of its study and standar disation, clashes where the ranking system of the word, played an essential role of study and understanding of the language as an element of power and identity.
\end{abstract}

Keywords: Regeneration, grammar, writing, language, proposition. 


\section{A razão e a linguagem, princípios para compreender a Regeneração a partir da língua: Miguel Antonio Caro}

\section{Resumo}

Este trabalho tenta refletir e propor o século XIX como um sistema de representação, e onde a atividade social retórica liderou o cenario político, o histórico e o social. Por isso mesmo, estes sistemas de enunciativos expoem, de forma clara e radical, uma espécie de esquemas de representação, que mostraram não só através da práxis do discurso mas também de seu estudo e padronização, confrontos onde o sistema de hierarquização da palavra, desempenhou um papel fundamental de estudo e compreensão da linguagem como um elemento de poder e identidade.

Palavras-chave: Regeneração, gramática, escrita, linguagem, proposição. 


\section{INTRODUCCIÓN}

Miguel Antonio Caro ocupo 30 años de su vida académica al estudio y conformación de una teoría en torno a la lengua; es bien sabida la influencia capital que el ámbito lingüístico tuvo sobre la construcción de las ideas de nación e identidad ${ }^{1}$. Es evidente que el intento de Caro por sistematizar el funcionamiento del lenguaje, obedece a la construcción de un régimen de representación cerrado y organizado que recoja todas las posibilidades sociales, cubiertas bajo el halo de la razón hispanófila (Escobar, 1998, pp. 31-32).

1 La actividad lingüística de Caro se inició en la década de 1860 y se prolongó hasta 1890, dividiéndose en dos etapas: la normatización del castellano como instrumento civilizador e identitario -materia de análisis en el presente artículo- y sus estudios latinistas. La producción del colombiano en relación con el estudio de la lengua, comenzó con su obra Un rebusco Gramatical (1860), este libro no fue publicado en su tiempo, fue sacado a la luz por el Instituto Caro y Cuervo bajo la supervisión de Carlos Valderrama Andrade en 1980. La primera publicación de un artículo de Caro que hiciera referencia al uso de la lengua fue Plural de los apellidos, el 11 de noviembre de 1864 en la revista católica La Caridad, en réplica a una discusión sostenida con Manuel María Mallarino. En 1870 su obra Tratado del participio, expone su teoría de comparación entre el latín y el castellano. Con motivo de la fundación de la Real Academia de la Lengua en 1872, publica en el Anuario Colombiano (1874) su discurso "Fundación de la Real Academia", donde enuncia que la lengua es un elemento identificador de una nación. Hacia 1878 (julio), hace referencia a la unión entre lengua y literatura en su texto Americanismo en el Lenguaje, visión que está influida por Schlegel y a la cual nos referiremos más adelante. Con la publicación, en 1881, de su discurso Del uso en sus relaciones con el lenguaje, pronunciado en la junta inaugural de la Real Academia, Caro evidencia la función de la lengua como lazo irrompible con España. A partir de este periodo, Caro radicaliza su posición hispanófila y contribuye con la edición anotada de la Ortología y métrica de Andrés Bello en 1882. Finalmente, cierra este periodo con la nota publicada el 15 de marzo de 1890 en la revista Colombia llustrada, de Bogotá, donde hacía referencia a trabajos de reciente aparición: Los Provincialismos de García Icazbalceta, y las Voces nuevas de la lengua castellana de Baldomero Rivodó. Sus estudios sobre el latín, se orientan más a su posición filológica, en donde adoptó esta lengua como suya, porque le permitía expresar mejor sus sentimientos, creencias e ideas políticas. Sobre esta etapa del pensador colombiano, no haremos una reflexión profunda en el presente trabajo, proponiendo su análisis para una investigación subsiguiente.
Dicha propuesta evidencia la necesidad de un análisis de estamentos como el lingüístico, no desde una dependencia política ni ideológica, sino como un engranaje, desde el cual se emanan los presupuestos que intentaron generar una nación más cercana a lo discursivo que a lo real. En este sentido, el presente trabajo no se limitará a describir los aspectos y acontecimientos históricos e ideológicos, que motivaron el surgimiento de la Regeneración con Miguel Antonio Caro a la cabeza, sino que tratará de dar cuenta de las influencias filosóficas y lingüísticas, que generaron el discurso nacional defendido por Caro. De tal modo, resultaría limitante proponer una estructura de dependencias inmediatas, entre el trasegar histórico colombiano y los estudios caristas sobre el castellano, por el contrario, es nuestra intención demostrar que dicho discurso es el que genera gran parte de la dinámica política e ideológica de este tiempo.

Por tal razón, hemos decidido dividir esta exposición en dos grandes partes fundamentales: una primera que hará alusión a las fuentes lingüísticas y filosóficas de las que bebió Caro, a la que hemos llamado modelos epistémicos ${ }^{2}$. En este sentido, los modelos a los que haremos referencia serán el Sensualismo y el Tradicionalismo; en el caso del Utilitarismo, haremos mención de él a través de la posición crítica que asumió Caro en sus escritos. Sin embargo, y como lo hemos explicado a través de Ingarden, los modelos epistémicos

2 Como lo explica Román Ingarden, los modelos epistémicos funcionan como representaciones conceptuales, como sistemas de conocimiento sobre los cuales se soporta el pensamiento o se indaga sobre la realidad. Por otro lado, dichos modelos representan un dinámica de influencias entre sociedades que se instalan sobre lo imitativo para llegar a lo adaptativo y decantar en lo crítico. Cf. Ingarden, R. (2004). La Obra de Arte Literaria. México: Taurus, Universidad Iberoamericana. 
son sistemas dinámicos que presentan una suerte de evolución en el momento de convertirse en paradigmas, en consecuencia, se hace necesario dar cuenta del proceso de influencia, su desarrollo y decadencia en la visión que, de la lengua, ha presentado Caro durante más de 30 años.

La segunda parte del trabajo hará referencia, precisamente, a la adaptación de dichos modelos en el contexto nacional; a la cual hemos denominado lugares de enunciación ${ }^{3}$, desde los cuales, la Regeneración propuso formas de aprehensión, memorabilidad y ética social, política y religiosa. De esta forma se evidencia, que los acontecimientos políticos no influyeron de manera unilateral sobre la posición lingüística y filosófica de Caro y sus compañeros de campo, sino que la teoría y el estudio de la lengua también ocuparon un lugar preponderante dentro de esta praxis social.

\section{Primer modelo epistémico: EL SENSUALISMO}

La querella entre antiguos y modernos bajo la discusión de la reforma instruccionalista, liderada por el sector liberal que propuso una educación laica, gratuita y pública, alejada del influjo de la Iglesia, marcó un acontecimiento esencial dentro de la posición

3 La noción de lugares de enunciación ha sido expuesta por varios teóricos como Walter Mignolo y Jhon R Gillis. Para el primero, estos escenarios se conforman luego de la adaptación de modelos de pensamiento hegemónicos o externos a la geografía social, de tal modo, que constituyen nuevos modelos discursivos a través de los cuales se construyen los imaginarios, en este caso, de identidad. Para Gillis, estos lugares de la enunciación se convierten en lugares y políticas de la memoria en donde se enuncia la tradición y el discurso que evidencia las posiciones desde la lengua, la religión y la ideología. Cf. Mignolo, W (1995). The Darker Side of the Renaissance: Literacy, Territoriality, \& Colonization, 2nd Edition (Paperback).Ann Arbor: University of Michigan Press, y Gillis, J. (1994).Commemorations: The Politics of National Identity, New Jersey: Princeton University Press de Miguel Antonio Caro, quien se presentó como uno de los más radicales opositores a dicha propuesta. La discusión dada entre 1848 y 1867, sobre el acto legislativo que imponía la filosofía utilitarista de Jeremías Bentham, y Los elementos de ideología de Antoine Claude Destutt dentro de universidades y colegios, también significó para Caro un terreno importante de confrontación ${ }^{4}$. Dicho panorama resultó desolador y preocupante para Caro, por tal razón escribe en 1870, un año después de publicar su Estudio sobre el utilitarismo, el informe que rindió frente al consejo de la (re) fundada Universidad Nacional de los Estados Unidos de Colombia llamado Elementos de ideología del conde de Tracy.

Para Caro, la presencia de Bentham y Dessut de Tracy, significó una peligrosa intromisión en la educación de corte religioso, por esta razón, el autor establece un informe que critica duramente el método usado por Tracy, cuestionando su posición en relación con la ideología, la gramática general y la lógica. Para Caro, la filosofía va en consonancia con el avance de la ciencia, sin embargo, no duda en aclarar que dicho progreso se encuentra condicionado por el progreso del espíritu

4 La adopción de Bentham y Tracy entre 1825 y 1826, sufrió varias modificaciones y censuras, que dependían del gobierno reinante. Por ejemplo, Santander los adopta en el 25 y Bolívar los suprime en 1828; luego de ser restablecidos por Santander en 1833, son reemplazados, durante el gobierno de Mariano Ospina (1844), por las obras de Jovellanos y Jaime Balmes. Finalmente, son restablecidos en 1870 por el congreso nacional.

5 Entre 1848 y 1867 modificaron su política de libertad absoluta de enseñanza, permitiendo que el Estado interviniera en la educación, hacia 1870, luego de la (re) fundación de la universidad, se contrató, como lo cuenta Oscar Saldarriaga (2004), una misión de 12 profesores alemanes que tuvieron a su cargo la formación de profesores bajo la premisa de la pedagogía objetiva o pestalozziana, fundada bajo los principios entregados por las gramáticas generales y razonadas, elaboradas a fines del siglo XVIII. El objetivo principal de dicha reforma apuntaba a lograr una "educación gratuita, obligatoria y laica". 
humano, por más variable y cambiante que éste pueda parecer. De este modo, la teoría común a principios del siglo XIX, en donde el relativismo de las nociones científicas que se alejaban de lo trascendente, como es el caso, según Caro, del Utilitarismo y el Sensualismo, se convertirían en simples modas pasajeras que no hacen justicia a la relación entre filosofía y progreso: "La experiencia, o mejor dicho, el examen de los fenómenos críticos observados por ella, demuestra no haber época ni pueblo en que no exista un fondo común de ideas morales aun a despecho de diversas circunstancias" (Caro, 1870, p. 137).

De esta manera, apoyado en Platón, Landriot, San Pablo y Goethe, reafirman que el mundo concreto de los descubrimientos científicos, eleva el espíritu humano a la fuerza trascendente y metafísica de la presencia divina. El mayor temor de Caro radicaba en que la problemática filosófica expuesta por sensualistas y utilitaristas, minaba el principio del orden divino que comandaba el pensamiento conservador; por otro lado, el "afán materialista" de estas corrientes podía llevar al mundo del conocimiento a decantar en cristalizaciones, que impendían cualquier posible relación entre lo concreto y las significaciones espirituales. Según Caro, el poder divino de la norma y de los gobiernos debería evidenciarse como el elemento de mayor legitimidad:

Caro tenía la convicción, y así lo expresó reiteradamente, que el poder soberano tiene origen divino y que la política sin bases morales y religiosas carece de fundamentos sólidos. Afirmó también que la cohesión de una sociedad tiene su mayor soporte en la tradición, que en el caso de los pueblos latinoamericanos era la tradición política y cultural española (Jaramillo, 2005, p. 25).

Por tal motivo, para Caro resultaba en extremo peligrosa la adopción de premisas y derroteros filosóficos que no tuvieran como guía la omnipresencia divina, y coincidía con el filósofo católico español Gaspar Melchor de Jovellanos (1744-1811), a quien leyó con avidez, en que el conocimiento humano era tan artificial como la subdivisión de las ciencias $y$, que por ende, resultaban imperfectos. En consecuencia, era inadmisible aceptar una educación fundada sobre el principio materialista de las ciencias, para lo cual era imprescindible unir el estudio de la literatura y de las "buenas letras", como las llamaba Caro, al de las ciencias, reduciendo las doctrinas económicas bentanianas en las matemáticas y las ciencias económicas. En cambio para los sensualistas, en específico para Tracy, como lo expone Caro en su informe, el método cartesiano desde el cual todos los fenómenos psíquicos superiores tienen su origen último en los sentidos, fundaba una doctrina, que desde el punto de vista gnoseológico es una forma de empirismo. Pero el empirismo no se limita solamente a la percepción sensible, mientras que el sensualismo entiende que ésta es la única fuente de conocimiento.

Miguel Antonio Caro pensaba que, el presupuesto de que toda la experiencia y el conocimiento se fundaban en los sentidos y llegaba a ellos resultaba inadmisible, pues en su concepto, la verdad y la norma obedecen no solo a los sentidos, sino que también radican en el espíritu. Según Caro, el Sensualismo desentendía toda autoridad y buscaba juzgar las cosas con independencia. Desde 
la perspectiva del pensador colombiano, el método resultaba inaplicable, pues es imposible prescindir de aquellos principios fundamentales que Dios ha puesto en nuestro entendimiento, desaparecer todo rastro de autoridad significaría renunciar a la guía divina, además de darle la espalda a una tradición, que según Caro, era el piso más fuerte sobre el cual podíamos sembrar la idea de una nación constituida. Incluso, el informe presentado ante la Universidad $\mathrm{Na}$ cional trata de demostrar que los mismos sensualistas se contradicen, al borrar todo vestigio de principio fundador: "El horror a la nada, horror del orden intelectual, a que en el orden moral corresponde el horror del pecado, volvióle a la autoridad, en cuyo terreno los sensualistas levantaron el edificio de su filosofía" (Caro, 1870, p. 312). Por tanto, para Caro siempre existirá un principio inmutable que trasciende sobre el propio orden de progreso de las ciencias y aún más de los sentidos.

Es en este escenario de discusión donde aparece una opción que demostrará el principio de autoridad divina promulgado por Caro: el lenguaje. Su reflexión toma como ejemplo el carácter general de la preposición, a partir de la cual el pensamiento individual se:

expresa con mayor soltura, pero siempre estará dependiendo de la fuerza inmutable de la norma general. Es decir, que la preposición nos obliga a dar a nuestras ideas una expresión formal uniforme y a mirar las cosas por un lado determinado. Norma esta providencial, que no estorba a la libertad de su ejercicio sino que la dirige, la orienta (Caro, 1870, p. 313).
En esta medida, el idioma materno es también una expresión de ideas inmutables, pues se ha desarrollado y fijado de acuerdo con las ideas propias de los pueblos que lo hablan, presentando, de cierta manera, una filosofía inconfundible y una expresión propia. Por ello, para Caro resulta contradictorio la tesis de Tracy: "pensar es sentir, hablar es sentir"; por el contrario, y haciendo eco de los presupuestos de Jovellanos, son las ideas sobre las sensaciones y los sentidos, las que están ligadas al genio de una lengua determinada, que no debe romper el lazo metafísico con la divinidad, ni con la entidad trascendente: "La sola circunstancia de hablar una lengua copiosa de vocablos abstractos es motivo de aficionarse a la contemplación de lo sobre natural" (Caro, 1870, p. 313). Caro presenta la lengua como una suerte de conexión racional con la divinidad, y el orden inherente a cualquier actividad humana. El hablar una lengua, y más aún conocer su estructura, significaba comprender de manera analítica el mundo que Dios, tan sabiamente, había creado.

La teoría racional-trascendente de la lengua, fue tomada por Caro de la teoría generada por la Escuela de Port Royal. A través de los principios expuestos por la abadía jansenista, reafirma su propuesta de la estructura binaria de los signos (significado y significante), de la relación inmediata con el mundo de las ideas y del espíritu. De acuerdo con los jansenistas, son los signos los que contienen en su interior la regla inmutable de la presencia de Dios. Para Caro, la tradición y la historia, representaban, en esencia, la presencia de dicho principio de autoridad y el estudio de la naturaleza humana, ya sea desde el espíritu o desde el mundo de la experiencia, necesitaba del auxiliar de la tradición para ser entendida en plenitud: 
"Porque no solo somos individuos conscientes de nuestra personal existencia, sino miembros de la familia humana, que tiene su propia historia. Nuestros semejantes vivos y nuestros antepasados son fuentes de instrucción y complementan el conocimiento reflejo en sus pesquisas sobre la verdad del alma" (Caro, 1870, pp. 314-315).

Por otra parte, esa aparente independencia del método sensualista de pretender llegar a la verdad sin recurrir a un auxilio ajeno, llámese principio divino, llámese tradición, resulta un índice de excesivo orgullo. Sin embargo, dentro del examen que hace Caro sobre la propuesta sensualista y de su método cartesiano, Descartes, al final resulta bien librado de sus juicios. Por una parte, la fuerza de su instinto resulta noble al no llevarlo a la negación de Dios, sino a la aceptación de su propia dependencia con la divinidad; además, Descartes guiado por su moral y rectitud supo levantarse de la apariencia para llegar a la esencia de lo trascendente. Así lo explica Caro: "Justificable y aun plausible, se presenta este orgullo, cuando no se vislumbra en él la soberbia satánica que niega la debida obediencia, sino la altivez del hombre que se forja una libertad absoluta para tener la complacencia de resignarla por sí mismo en manos de Aquel a quién lo debe todo" (Caro, 1870, pp. 316-317).

\section{LENGUA E IDEOLOGÍA: UNA CRÍTICA A LA CONCEPCIÓN INDIVIDUAL DEL SENSUALISMO}

Ya hemos hecho referencia a que uno de los puntos que Caro crítica con más ahínco, es precisamente la negación que hace el Sensualismo de la inteligencia divina. Pero otro punto esencial, en el informe presentado por el pensador en torno al sensualismo, es el de la gramática, y más en concreto el del origen del lenguaje. Para Caro los dos sistemas enunciados por los filósofos -imitación del hombre a otros seres, e interjección como origen instintivo de la palabra- propuesto por Max Müller, resultan teorías incompletas que no logran vislumbrar un camino claro hacia el origen del lenguaje, y el uso de éste en el mundo de la experiencia y la fe. Caro completa dicha teoría al añadir que aquel instinto, raíz común del origen del lenguaje, es conferido por Dios.

De esta manera, Caro reafirma su posición en relación con la necesidad y la coherencia de la escuela filológica comparada, y su afición por la teoría lingüística de Friedrich von Schlegel ${ }^{6}$. En palabras del propio Caro: "No concibo que pueda tratarse esta materia sin las luces de la filología comparada; más digo, es la filología misma despojada de la documentación lingüística y revestida de fórmulas filosóficas" (Caro, 1870, p. 350). Para Caro, el tronco común de las lenguas propuesto por Schelegel y la filología comparada, supera la posición de la teoría instintiva de la interjección; es decir, el lenguaje deviene de un misterio divino común, pero no se queda en el mero escenario oscuro de la sin-razón. Como lo explica en su trabajo Del uso en sus relaciones con el lenguaje (1881), la limitación del origen del lenguaje solo en las interjecciones, conduciría a una

6 Para Schlegel todas estas lenguas (el griego, persa, latín, germánico y de modo más reducido lenguas eslavas, el armenio y el céltico) están vinculadas genealógicamente, todas devendrían del sánscrito. Considera que las lenguas humanas se pueden subdividir en dos tipos fundamentales según su constitución: lenguas flexivas (aquellas en que aparece la modificación de la raíz) y lenguas aislantes. Generalmente, esta bipartición se desarrolló en una distinción triple: lenguas flexivas, aglutinantes y aislantes. Esta reinterpretación es de August Wilhelm (hermano de Schlegel), seguido luego por Schleicher. 
concepción del mismo alejado de la razón y volcado hacia la afectividad ${ }^{7}$.

El hecho de que de Tracy cifre sus principios sobre el origen instintivo del lenguaje, y le confiera a la naturaleza del verbo un origen absoluto desde la interjección, es en donde reside la mayor falencia del pensamiento sensualista según Caro. En esta medida, para Tracy la esencia de todo verbo es ser, y su principio se encuentra íntimamente ligado con una sensación o afección de cualquier naturaleza. Para Caro, en cambio, la esencia de todo verbo es siempre una idea, que claro, deviene del principio divino; esto es, la idea del origen del lenguaje expuesta por Tracy, resulta para Caro, una suerte de teoría que se quedó a medio camino. Por esta razón, es fundamental basar el conocimiento de la lengua castellana desde su relación con el latín y desde su conformación más alta: la literatura. En este punto se encuentran Caro, Andrés Bello y Gaspar Melchor de Jovellanos. En el Discurso pronunciado en la instalación de la Universidad de Chile en 1843, Bello enunció el sentido y la importancia que tenían los estudios literarios dentro de la formación de una identidad:

Aquel departamento literario que posee de un modo particular e inminente la cualidad de pulir las costumbres, el lenguaje, haciéndolo vehículo fiel, hermoso, diáfano de las ideas (...); que, por la contemplación de la belleza ideal y de sus reflejos en la obra del genio, purifica el gusto, y concilia con los raptos audaces de la fantasía

7 En este punto Caro coincide con la última parte de la teoría expuesta por Max Müller según la cual el lenguaje comienza cuando el sentido instintivo de las interjecciones terminan. Para Caro el gran apoyo de esta etapa del lenguaje es, precisamente, la tradición. los derechos imprescriptibles de la razón; que, iniciando al mismo tiempo el alma en estudios severos, auxiliares necesarios de las buenas literatura, y preparativos necesarios para todas las ciencias, para todas las carreras de la vida, forma la primera disciplina del ser intelectual y moral, expone la leyes eternas de la inteligencia a fin de dirigir y afirmar sus pasos y desenvuelve los pliegues profundos del corazón, para preservarlos de extravíos funestos, para establecer sobre sólidas bases los derechos y los deberes del hombre (Bello, 1881, pp. 310-311).

La posición de Bello coincide con la propuesta hecha por Caro y, claro está, con la fuente de la que beben los dos americanos: la del español Jovellanos, al cual haremos referencia más adelante. Así pues, la literatura renuncia a la posición individual, instintiva y subjetiva propuesta por el Sensualismo y por el Romanticismo. Su función, por el contrario, debe ser pública y didáctica, convirtiéndose en la puerta de entrada a la razón, condición necesaria para la vida civil y para la formación del ciudadano ideal. Como ya se dijo anteriormente, tanto para Bello como para Caro - sobre todo en el estudio que escribe sobre el Utilitarismo (1868)- la literatura es la base de todas las ciencias, y es la que logra preservar el lazo necesario entre sujeto intelectual y sujeto moral.

Dentro de la propuesta de Bello, se encuentra la voz imprescindible de Jovellanos y su propuesta pedagógica, dentro de la cual también resultaba neurálgica la presencia de la literatura. Gaspar Melchor de Jovellanos reelaboró el concepto de razón, tal como fue característico en el movimiento 
ilustrado europeo del siglo XVIII ${ }^{8}$. De esta manera, Jovellanos entendía la razón, ya no como un ente preexistente gobernado de forma misteriosa por Dios, sino como un movimiento del espíritu o una fuerza activa del propio ser humano: "esta razón no es un ser, sino cualidad o facultad de nuestra alma; esta facultad no supone conocimientos sino disposición para adquirirlos" (Jovellanos, 1797, p. 21). Tal como lo explica Santiago Castro-Gómez (1996), en apariencia, podríamos pensar que la propuesta de Jovellanos estaría en concordancia con la expuesta por el Sensualismo, en relación con que el hombre, a pesar de ser una criatura sensible, debe, sobre todas las cosas, atenerse a la razón. Como lo expone de Tracy:

El juicio de la verdad y la norma no pertenece exclusivamente a los sentidos, sino al espíritu: no es veritates judicios in sensibus. Esta certidumbre que puede proporcionar los sentidos se extiende muy lejos, y hay muchas cosas que uno cree saber por su intermediario, y de las que no se tiene plena seguridad. Por tanto, cuando el testimonio de los sentidos contradice o no hace contrapeso a la autoridad de la razón, no se plantea el problema de si se debe optar: en buena lógica, hay que atenerse a la razón (Tracy, 1871, p. 80).

El planteamiento de Tracy resulta contradictorio de acuerdo con la posición que ha asumido Caro frente al Sensualismo, presentándolo como una teoría limitada por la percepción empírica, y por el papel principal

8 Para ampliar el proceso de reelaboración del concepto de razón Cf. Cassirer, E. (1932). "La forma de pensamiento de la época de la ilustración", en Filosofía de la ilustración. México: Fondo de Cultura Económica. que cumplen los sentidos en el conocimiento del mundo. Es claro que para Tracy, como para los demás sensualistas, el primer acercamiento al mundo se hace a través de lo que Helvetius llamó sensibilidad física9 ${ }^{9}$ pero no es el último escalón de la percepción humana y del origen del lenguaje. Para Caro, uno de los grandes problemas que presenta el Sensualismo desde su posición gramatical, se sitúa precisamente en la razón y el juicio, conceptos que, según el pensador colombiano, resultaban banales desde la percepción de $\operatorname{Tracy}^{10}$, pues ya había demostrado que el lenguaje no devenía exclusivamente de imitación, ni tampoco se situaba en el terreno de las intejecciones; si fuese así en nada se diferenciaría el lenguaje humano del animal:

El lenguaje humano es el lenguaje por excelencia, porque no es sólo el espíritu que habla con el espíritu sino además el hombre que habla con Dios y de Dios. El hombre ora. El hombre predica. Y en el desempeño de estas funciones es precisamente donde la palabra adquiere su mayor elocuencia y su mayor eficacia. Orar es aspirar el ser finito al ser infinito, la oración es la escala de Jacob y con palabras oramos (Caro, 1881, p. 130).

9 El Sensualismo, aunque no tiene ninguna teoría autónoma, no puede dejar de recurrir a estos problemas, ya que tiene como objetivo el estudio del ser humano y todo aquello que lo rodea, incluyendo el lenguaje. Para Helevetius, el hombre posee la facultad de recibir diferentes impresiones, lo que denomina sensibilidad física (120: 1758). Por otro lado, para Tracy, los objetos fijados por la sensibilidad física se instauran en el devenir humano a través de la memoria, en consecuencia, el Sensualismo también genera una suerte de propuesta desde la tradición, con la diferencia de que dicha entidad no depende solo de la fuerza divina y trascendente, sino de la pragmática en la realidad.

10 Para Caro, el sensualismo define el juicio como una simple relación de sensaciones. 
Pero si para los sensualistas el conocimiento del mundo podía representarse en una suerte de esquema binario (sensibilidad física/memoria), para Caro dicha idea resultaba análoga, solo que los elementos que conforman la estructura no son los mismos de Helvetius y Tracy. Por un lado, es bien sabida la fidelidad de Caro por el modelo hispánico, por otro, su lealtad al pensamiento y a la fe católica, en donde seguía perviviendo un fuerte rezago del pensamiento escolástico. Entonces, el esquema binario descrito por Caro se enlaza con el propuesto por San Agustín, recordemos que el colombiano fue un ávido lector de San Agustín, incluso sobre otros doctores de la iglesia como Santo Tomás. Así lo describe Caro en su obra publicada en 1903 "El partido Católico":

Es evidente que el santo de la iglesia más sabio y quien hizo referencia a la mayoría de temas que a este pobre principiante interesan, fue san Agustín. El maestro silencioso diría que de Dios no viene la verdad, él es la verdad, y todo lo que el Hombre haga vendrá de él e irá a él. La razón y la fe son una misma, viven en la armonía del cielo trascendental (Caro, 1903, p. 25).

Según Caro, la fe y la razón deben vivir en un movimiento armónico que propone el conocimiento en dos etapas: presencia y experiencia, nociones presuntas y nociones adventicias ${ }^{11}$. Según esta percepción, y volviendo al concepto de trabajo y actividad mental agustiniano, para el filósofo colombiano, la única forma como el Hom-

11 Las nociones presuntas o presunciones, corresponden a la traducción latina de Séneca - praensumptiones-, de las "prolepsis"estoicas- anticipaciones o presunciones. bre adquiere la ciencia es a través del trabajo mental y reconociendo el trabajo de otros, siempre y cuando dicho trabajo no riña con la fe. En este sentido, es la noción de presencia la que representa a Dios, y la que, según Caro, sale perdiendo en la percepción sensualista ${ }^{12}$ : "si ella no existiese [la presencia] ¿cómo podríamos formar ideas genéricas, orgánicas de la inmensidad que nos rodea extendiéndose más allá del alcance de nuestra experiencia?" (Caro, 1952, p. 313). Por tanto, el planteamiento sensualista de que el lenguaje surge por una dinámica instintiva y desde la inducción, no puede limitarse; cómo hablar del origen sin hablar de la inmensidad y de lo eterno. Miguel Antonio Caro replica de la siguiente manera hacia el concepto sensualista de la inducción y la interjección: "quien dice inducir dice adivinar en fuerza de presuposiciones naturales [instinto, imitación, interjección]. Con la sola experiencia acumularíamos datos parciales sin número, pero nunca osaríamos interpretarlos como indicios de leyes generales" (Caro, 1952, p. 313). Otro elemento importante al que hace referencia Caro, valiéndose de Claude Bernard, es la supremacía de la presencia divina. Ésta ha estado sobre la propia experiencia científica, reafirmando su enunciado en torno a la "limitante" teoría sensualista; incluso expone la manera como la inducción es anulada de forma contradictoria, por la doctrina de Tracy:

porque la inducción supone precisamente los que no puede haber pasado por los sentidos, a saber, el tránsito de las cosas sentidas a las cosas metafísicas;

12 Recordemos que para los sensualistas el sentido de presencia y autoridad divina desaparecen, y se replantea a través de los sentidos. 
pues como nota exactísimamente Aristóteles distinguiendo la sensibilidad de la inteligencia, el ejercicio de aquella sólo concierne a lo particular, mientras ésta se eleva a lo universal. Ni la idea universal, ni el paso mediante el cual la adquirimos, son efecto de las sensaciones (Caro, 1952, p. 314).

De esta manera, el vínculo entre las cosas sentidas y las cosas metafísicas no es otro, para Caro, que el lenguaje, fruto de un entendimiento "que inquiere insaciablemente lo universal" (Caro, 1952, p. 315), y que lleva dentro de sí la necesidad innata de lo universal, de lo absoluto, de Dios. Es así como el lenguaje es resultado de unas ideas innatas que han trascendido, por su sentido metafísico, el ámbito de los sentidos y han dado lugar a un constructo del lenguaje en donde conviven la razón y la fe: “Dios, habiendo creado todos los seres los unos para los otros, con inclinaciones y capacidades armónicas, sólo hubiese dejado a la inteligencia humana desprovista de toda noción predisponente, desorientada, digámoslo así, en medio del orden universal" (Caro, 1869, p. 45).

Dicho orden universal no resulta misterioso para el Hombre, sino que es el fin de su camino cognitivo y axiológico. Tal y como lo ha descrito Jovellanos, la razón resulta el sendero más rápido y seguro para que la humanidad llegue a dicho orden y lo imite en la tierra; el lenguaje se convierte en la luz más brillante para reflejar y preservar el orden. Por tal razón, el principio de autoridad que define la relación entre fe y razón, tiene su mejor aliado en la enseñanza de la lengua como un reflejo directo del orden, y de su utilidad dentro del ciudadano que se formaba en el ideario conservador ${ }^{13}$. La relación entre razón y fe, otro asunto fundamental para Caro, aseguraría la armonía a la que llamó el "bello ideal"14.

Lo que resultaba para Caro como el ideal y la esencia del arte, también funcionaba para la lengua, expresión absoluta del entendimiento y muestra clara de que las ideas innatas eran reflejo de la autoridad divina. El don divino del lenguaje (parte fe, parte razón), está constituido por los axiomas necesarios y absolutos, cuya aceptación resulta inmediata, y se transforman, desde la norma, en maneras de proceder y principios morales. Dentro de las ideas innatas cabe destacar la idea misma de Dios, que como es lógico, significa la idea de Dios cristiano visto desde la orilla de un cartesianismo, traducido al acomodo de las intenciones expresadas por Caro:

13 Es bien sabido, que uno de los principales objetivos del movimiento de la Regeneración que encabezó el presidente Rafael Núñez, era ordenar y unificar un país alrededor de un Estado autoritario y de la Iglesia católica. En gran medida, esta receta para reorganizar el territorio nacional emergía de un diagnóstico sobre las condiciones creadas por la constitución liberal y federalista de 1863, que había otorgado no sólo gran cantidad de libertades sociales, sino también casi autonomía absoluta a las provincias con el consecuente debilitamiento del poder central. La lengua, en este sentido, se convirtió en una de las herramientas del plan unificador y centralizador de la nación, y en el mejor argumento para generar una tradición que reafirmará el lazo "irrompible" con España.

14 Para Caro, el conocimiento es inconcebible sin la virtud; el primero, jamás podrá funcionar sin la segunda cualidad. Al armonizarse, se produce lo que denominó el bello ideal, el mismo que representa la esencia del arte. Desde esta perspectiva, encontramos otra relación entre San Agustín y Caro. Para el santo, la fe y la razón se armonizan a través de la virtud. Ésta se presenta como el vaso comunicante entre el conocimiento que se obtiene desde los sentidos y el que se obtiene desde la razón. Dicha teoría fue denominada por San Agustín como "la iluminación". Cf. Para Wills, G. (2001). San Agustín; traducción de Teófilo de Lozoya. Barcelona: Mondadori. 
Quiso Descartes poner en ejecución la idea de fundar la independencia del pensamiento, y empezando por excluir todo principio que se apoyase en argumento de autoridad, acabó por encasillarse en el sabido entinema: pienso, luego existo. Graduado de principio absolutamente libre, es decir, de cosa completamente suya, pero andaba equivocado. ¿Era él por ventura el autor de su certidumbre? ¿Había él creado los motivos de su fe? Cuando afirmaba pienso, luego existo es evidente que confiaba en la veracidad de una lógica cuyos principios no había creado él, cuya solidez misma no acertaba él a explicarse. En resolución daba oídos a una voz, o fuese ley de su entendimiento, o imperio de la tradición, o finalmente inspiración, pero en todo caso hija de autoridad que le decía: has hecho un buen silogismo (Caro, 1870, pp. 444-445).

Como se explicó antes, la falta más grave que comete Descartes, es precisamente negar el principio de autoridad y las ideas innatas, aunque la relación de Caro con el modelo cartesiano resultaba ambigua, la idea de veracidad, por ejemplo, fundamental para Caro, resulta análoga a la idea de veracidad divina enunciada en la tercera Meditación cartesiana, y después de la segunda muestra de la existencia de Dios. Aunque no olvidemos que Caro "salva" a Descartes al presentarlo como un pensador, que no cayó en la negación y superó su falta a través de su virtud.

\section{EL PRINCIPIO DE AUTORIDAD: LA NORMA DIVINA}

Plantear el principio de autoridad desde el cual se abre el camino al conocimiento, la necesidad de una norma paradigmática, modélica - como resulta el latín para el castellano-, se convertía en garante de una tradición ${ }^{15}$. Desde este escenario, es clara la oposición entre las expresiones del individualismo, que se distanciaban del principio de autoridad como el Sensualismo. Dicha oposición entre los procesos individuales y conservadores, encontraron en el lenguaje el fundamento del misterio de la vida, de la causa primera, del origen divino de la norma que preserva el temor y busca el orden como causa y efecto de la construcción discursiva. En este sentido nos volvemos a encontrar con Jovellanos, para quien resulta de vital importancia la lucha contra la subjetivización del mundo, por medio del recurso de la imagen autoritaria de Dios:

Jovellanos trata de fundar la subjetividad y la libertad sobre las bases del autoritarismo divino, con lo que su problema es similar al que enfrentaban los más liberales desde una óptica secularizada. No es que los escritores ilustrados de la península o del continente fueran ajenos a los problemas que planteaba la subjetividad, sino que ellos pensaban es ésta debía fundarse en un criterio unificado y en el temor a la autoridad divina, lo que implicaba una religiosidad "racionalmente" aprobada como necesaria y útil (Gordillo, 2000, p. 55).

15 A partir de la filología comparada, los idiomas establecían diferencias entre sí como el carácter, la articulación particular de las palabras, su gramática. Pero siempre resultaba necesaria la presencia de un tronco que garantizará la raíz de cada una de ellas. Cf. Foucault, M. (1966). Las palabras y las cosas. Una arqueología de las ciencias humanas. México: siglo XXI editores. 
Para Jovellanos y Caro la bondad del hombre es una idea innata; sin embargo, las ideas de la sociedad moderna son las que corrompen al individuo y llevan a la sociedad al caos. Por tal motivo, es primordial tener un modelo identitario y paradigmático que cumpla dentro de sus procesos con el ideal cristiano. España cumpliría con todos los requerimientos enunciados: "España, en los tiempos modernos, es quizá la nación en que más tarde ha aparecido la crítica; y esto precisamente porque es una nación de carácter propio, personal; nación eminentemente poética, eminentemente heroica y creyente" (Caro, 1888, p. 119).

La península Ibérica, cumple entonces con dos de las características que resultan esenciales en la propuesta de Caro y Jovellanos: ser creyente y tener un carácter propio que se relaciona y deviene del espíritu nacional. Es decir, resulta evidente que la poesía en España es una entidad innata, que proviene de la fe y no "del espíritu novelesco y falaz de los franceses" (Caro, 1888, p. 120). Para Caro, las leyes de los hombres y la ley natural, cualquier vivencia del individuo por el individuo en sí mismo, resulta imperfecta y al servicio de intereses personales que fragmentarían la nación y la sumergirían en el caos; por esta razón, el lenguaje debía regirse a la estandarización de un modelo normativo que lo libraría de "la falsa ilustración que adulando las pasiones del individuo, alentaba a la corrupción y al desorden" (Caro, 1888, p. 122).

\section{SEgundo MOdELO EPISTÉMICO: EL TRADICIONALISMO}

Es bien sabido que la relación y articulación entre lengua y política, resultó fundamental en la formación de los Estados nacionales. La voz de Jovellanos resultó primordial dentro del ideario de los conservadores, centrado en el fortalecimiento del lazo entre lenguaje, el pensamiento y la fe. Por esta razón, la irrupción del español Jaime Balmes ${ }^{16}$, exponente del Tradicionalismo francés, sumada a la presencia de pensadores como Fénelon y Gratry, reafirmó la idea aristotélica que aseveraba la relación entre expresión y ejercicio político. De esta manera "ser político, vivir en una polis, significaba que todo se decía por medio de palabras y de persuasión, y no con la fuerza y la violencia" (Arendt, 1998, p. 39) ${ }^{17}$ :

En sus dos definiciones más famosas, Aristóteles únicamente formuló la opinión corriente de la polis sobre el hombre y la forma de vida política y, según esta opinión, todo el que estaba fuera de la polis - esclavos y bárbaros - era aneu logou, desprovisto, claro está, no de la facultad de discurso, sino de una forma de vida en la que el discurso y sólo éste tenía sentido y donde la preocupación primera de los ciudadanos era hablar entre ellos (Arendt, 1998, p. 41).

Recordemos que la unión entre lenguaje y política es uno de los preceptos más importantes para los conservadores colombianos, y que el Tradicionalismo sirvió como

16 En el libro de Balmes El criterio (1844), se entrevé una de las formas que adquirió la tendencia conservadora basada en el tradicionalismo; se trata de universalizar la realidad y el criterio de verdad desde la óptica autoritaria y dogmática de la iglesia católica. El personaje creado por Balmes es el asustado Eugenio, que huye de la influencia terrible de corrientes que distraigan su contemplación "pura" y silenciosa de la obra de Dios.

17 Arendt explica que la definición aristotélica del hombre como zoom politikon sólo se puede entender si se agrega la segunda definición del hombre como zoon logon ekhon ("ser vivo capaz de discurso") 
respuesta y reflejo perfecto de sus propuestas ideológicas ${ }^{18}$.Por tal motivo, la conformación de un Estado-nación (comunidad modelo del siglo XIX), requiere la presencia de un lenguaje político - nacional y hegemónico - . La idea central a partir de la cual se consolidó el lenguaje político del siglo XIX, en lo que hoy es Colombia, no puede ser otro fenómeno que la Regeneración y el enfrentamiento que inicia contra las corrientes liberales galas: En palabras de Malagón Pinzón: "Estos ideólogos conservadores, basándose en las encíclicas de Pío IX, Quanta Cura y el Syllabus, intentaron implantar una situación bastante cercana a la que se presentaba antes de la Independencia, para poder eliminar de raíz la influencia del liberalismo francés" (Malagón, 2007, p. 35).

Como lo explica José Luís Romero (2001), el pensamiento conservador era, en su raíz, profundamente contradictorio y a pesar de la negación tácita que proclamaban en torno al pensamiento francés, el cuerpo retórico de la constitución de 1886, para el caso colombiano, evidencia una influencia francesa. Se acogieron ideas como la de la Soberanía Nacional, noción que se retoma de lo que se había estipulado en la Constitución de $1843^{19}$. Muestra de ello, es que la idea de

18 Al igual que la Regeneración, el tradicionalismo en España surgió como una respuesta a corrientes del mismo tamiz. Cuando el carlismo fue derrotado, la reina se inclinó por un régimen constitucional preferido por los liberales. Entonces la porción tradicional que había permanecido a su lado, desertó para pasarse al carlismo, único sistema que llevaría a la práctica el absolutismo buscado por ellos, tan pronto subiera el pretendiente al trono e hiciese realidad el lema de Ios tradicionalistas: "Dios, Patria y Rey». Al igual que la Regeneración, el Tradicionalismo proponía una Restauración basada en la fe católica y en el poder del rey como expresión de la norma divina. Cf. Galindo Herrero, S. (1956). Breve historia del tradicionalismo español. Madrid: Publicaciones Españolas.

19 El artículo 2do. de esta Carta prescribía que "La Nación granadina es para siempre esencial e irrevocablemente soberana, libre e soberanía nacional, de raigambre liberal, se convierte en un deber conservador y se limita a través del derecho natural:

La soberanía nacional o poder público, limitada por el derecho natural, se ejerce por órganos diversos, que específicamente llamados poderes, limitados de igual modo, independientes por la naturaleza definida de las funciones que a cada cual corresponden y armónicas en sus relaciones recíprocas conforme al principio y a los fines que le son comunes (Caro, 1932, p. 244).

Las ideas de centralismo, la sujeción de los derechos humanos al texto legal y la idea de la codificación ${ }^{20}$, entre otros aspectos, son claramente herencias del pensamiento Galo; sin embargo, todas fueron traducidas al lenguaje del pensamiento conservador atravesado por el Tradicionalismo español. Así se evidencia, a pesar del rechazo que producía sobre algunos sectores la influencia española luego de la Independencia, en los ojos de ciertos letrados, que se volcaron con más fuerza en la "madre patria".

El lenguaje de la Regeneración emergería como el más apropiado, para que la elite letrada promoviera la intervención del estado sobre la vida de los nacionales. Es así propone una serie de políticas que intentaban

independiente de toda potencia o dominación extranjera, y no es ni será nunca el patrimonio de ninguna familia ni persona". Restrepo Piedrahita, Carlos. Constituciones Políticas Nacionales de Colombia. Bogotá Universidad Externado de Colombia. 2003. p. 215.

20 La Codificación en Colombia comenzó en 1859, cuando éramos un Estado Federal, y algunos de los Estados Federados adoptaron el Código Civil realizado por Andrés Bello. Este se nutrió del Código de Napoleón de 1804 más otros componentes de Derecho Romano y de Derecho Español. En el año de 1887 se adopta para todo el territorio nacional el Código de Bello. 
regularizar y administrar la vida de los sujetos (Melgarejo, 2010). La Regeneración pasó a convertirse entonces en un modo de nombrar un proyecto, cuyo objeto era fomentar prácticas sociales propias de la clase dirigente. La necesidad de "limpiar" la lengua a través de la gramática, el alma a través de la moral y el cuerpo por medio de los manuales de urbanidad, hace parte de todo un programa de regeneración nacional. A partir de esta idea se construye un discurso político con una comprensión particular de la vida social, ligada a los centros de poder estatal y unas políticas sobre el cuerpo y el comportamiento correspondientes a la formación de sujetos nacionales, así como modos específicos de reconocer la población y el territorio. Una de esas estrategias se evidenció a través de la inauguración, en 1872, de la Real Academia de la Lengua. Para Miguel Antonio Caro, el propósito de esta institución era:

Propónese, por tanto nuestra academia estudiar el establecimiento y las vicisitudes del idioma en la nación colombiana, y honrar la memoria de los varones insignes que en ella lo cultivaron con decoro en épocas pasadas, ya fuesen venidos de la península, ya nacidos en el país, redimiendo a un ingrato olvido las noticias concernientes a sus vidas, que sea dable adquirir, no menos que sus principales obras. Hasta donde alcancen sus facultades, ella desea ilustrar la historia de la literatura patria, y cooperar a la formación de la biblioteca completa de nuestros escritores ilustres (Caro, 1952, p. 95).

Como lo explica Malcom Deas (1993), fue por medio de la gramática como se rehabilitó la presencia e influencia hispánica en nuestro país. Muestra de ello es que todas las obras escritas en este periodo, en torno a temas del lenguaje y que se enviaron a España, fueron reseñadas con tono muy positivo por Marcelino Menéndez y Pelayo, quien reafirmó que Bogotá era la "Atenas Suramericana"21. La idea de re-generar tomó más fuerza y se situó sobre la metáfora de ordenar, pacificar, disciplinar y educar; así pues, fueron los tradicionalistas, por medio de la idea de "limpieza lingüística", quienes tomaron la bandera de enseñar a través de la gramática y la religión. Muestra de lo anterior es el artículo 38 de la constitución de 1886: “La Religión Católica, Apostólica, Romana, es la de la Nación; los poderes públicos la protegerán y harán que sea respetada como esencial elemento del orden social" (Restrepo, 1995, p. 396). Más adelante, en el artículo 41, dedicado al aspecto educativo, vincularía también a la iglesia dentro de los procesos de enseñanza: “La educación pública será organizada y dirigida en concordancia con la Religión Católica. La instrucción primaria costeada con fondos públicos, será gratuita y no obligatoria" (Restrepo, 1995, p. 398). Con la relación entre enseñanza y religión, el conocimiento de la lengua tendría para Caro el tono trascendente que lo acercaría a las ideas innatas:

Nuestro entendimiento, aquel que trasciende la idea de conocimiento y experiencia, inquiere insaciablemente lo universal, lo comprensivo, sin duda porque lleva consigo mismo la necesidad de eso que busca. Hay algo en

21 Quien llamó por primera vez a Bogotá la Atenas suramericana fue el francés Eliseo Reclus, autor de un artículo en la Revue des Deux Mondes en 1864, en el cual le otorga esa denominación a nuestra capital y Buenos Aires (Montenegro, 2003). 
nosotros algo que nos mueve a investigar, y por ciertos caminos especiales, la razón última de las cosas; cualquier fenómeno que se nos presente nos mueve irresistiblemente a preguntar: ¿por qué será esto así? Y quedamos satisfechos con una respuesta que, sin explicarnos la naturaleza misma del fenómeno nos reduzca a una ley ya conocida por nosotros; no podemos prescindir a esta tendencia a generalizar, no podemos emanciparnos de algo que reside dentro de nosotros, armónico con el orden universal exterior (Caro, 188, p. 130).

De esta manera, el lenguaje se convierte en parte de las ideas innatas, pero se diferencian de los instintos (interjección) porque aceptan y devienen del principio de autoridad y orden divino; éste se convierte en aquello que está instaurado en el alma", y que guía el conocimiento como una presencia que supera la experiencia. Por tal motivo, Caro siempre tuvo presente que habría un modelo más cercano a lo universal, y otro más primario y empírico que alejaba al Hombre de Dios y lo acercaba a "las falsas sensaciones de un alma que existía más allá del Padre" (Caro, 1881, p. 131)"22. Ese modelo de orden racional superior no sería otro para Caro que la Gramática General, en cuyo punto se encontraría de nuevo con el tradicionalista Jovellanos.

22 Para Caro existían dos tipos de orden racional, uno superior y otro inferior. El primero, se instalaría en la inteligencia comprehensiva, que seguía un modelo superior; el segundo, está relacionado con el instinto y la sensación que niega el principio de autoridad. De este modo, la gramática general estaría más cercana al orden superior, por reconocer en el lenguaje una forma de limpiar el alma y de reflejo del origen divino de la norma.
Tanto para Caro como para Jovellanos, solo la gramática general aseguraría el buen gusto en el decir, resultado que traería consigo la posibilidad de educar el pensamiento y de "regenerar" a los ignorantes. De igual modo, la gramática general estudiaba la manera de decir el mundo, y en esa medida se convertía en la cifra de un orden racional superior, a través del cual el orden de las palabras, unas tras otras, sucediéndose en el tiempo, representaban la simultaneidad de un orden universal que debería conservarse para evitar la catástrofe. Caro defendía la creencia de que "es posible una mirada pura, primigenia, sobre las cosas" (Caro, 1881, p. 132), esta mirada pura solo puede expresarse a través de un lenguaje que duplica el pensamiento, lo representa. En consecuencia, la gramática general debería estudiar su orden y presentarse como conocimiento formal y abstracto que, al superar la peculiaridad de las lenguas, se acercaba más a una suerte de lógica. Sin embargo, no se trataba de una propuesta que se limitara a la relación entre ideas y orden superior, sino que planteaba el estudio de las distintas operaciones entre los signos del lenguaje, de su relación con las ideas y con el mundo sensible de donde provenían, por lo cual, era considerada como una ciencia de la naturaleza.

Consideramos que todo el cuerpo que conforma la Regeneración podría traducirse en esta idea de gramática, en ese sentido retórico que se transforma en un lenguaje peculiar, un nuevo modo de pensar el mundo, sobre todo en cuanto a la relación entre nación (como pueblo) y Estado (como proyecto político). La primera debía ser ordenada como cuerpo a través del orden superior racional, y de un aparato metódico, relacionado y cohesionado como la gramática 
general. De este modo, solo los letrados podrían guiar este proceso y, además, se encontraban en un lugar privilegiado dentro del escenario político, y serían los llamados a perpetuar esta arquitectura del poder.

\section{LO BELLO: EL PRINCIPIO DE LA PROPOSICIÓN}

Para Miguel Antonio Caro la concepción de lo bello se relacionaba directamente con la obediencia a la norma. La belleza no solo era el reflejo de un orden superior, macrocósmico y misterioso, sino que se relacionaba con la calidad de los valores políticos y morales; por esto, si el uso del lenguaje era el correcto, se evidenciaría un pensamiento ordenado y cercano a lo bello. Así, el lenguaje debía reflejar ese "orden armónico" del cual se ha hablado, donde confluye la razón humana y el orden divino de la norma. Es así como la función del lenguaje, en concreto el artístico, ya no se limitaba a reflejar de forma desnuda la naturaleza, sino que contaba con la capacidad de representar las cosas aproximándose a su pureza inicial, y debía producir un orden placentero. Por tanto, en la contemplación de la obra de Dios, se destacaba la variedad de combinaciones que podían existir en el lenguaje:

De suerte que Dios, de mil maneras diferentes y con innumerables y diversísimas combinaciones de las partes, puede hacer hermosísimas caras. Pero los hombres, reglando inadvertidamente la inmensa amplitud de las ideas divinas por la estrechez de las suyas, han pensado reducir toda la hermosura aun a combinación sola, que muchas veces, pasa de largo por el orden divino (Caro, 1881, p. 134).
A pesar de que en esta cita Caro estaría abogando por una suerte de libertad creativa en el uso del lenguaje, no podía, en ningún sentido, transgredir el modelo que recordaba a Dios. Dicho modelo no era otro que el de la tradición: "La interpretación que en virtud del lenguaje hace de las leyes sobrenaturales y del entendimiento comunica, directamente, la sensibilidad con la tradición" (Caro, 1869, p. 122). Desde esta perspectiva, aparece otra función que Caro atribuye al lenguaje: la credibilidad irreductible en la veracidad de Dios, que presenta como principio de toda certidumbre, como inicio de obediencia y anulación de todo aquello que anteponga el ingenio humano al divino: "La sola desconfianza de nosotros mismos es el escepticismo; unida a la confianza en Dios es la religión" (Caro, 1869, p. 128).

Desde el sentido de la veracidad de Dios, aparece nuevamente, la teoría de la preposición que expusimos anteriormente ${ }^{23}$. Para Caro, el funcionamiento de la proposición es el reflejo de las operaciones intelectuales y expresa el juicio, el entendimiento $y$, en consecuencia, el orden armónico. Por ejemplo, el uso nominativo del sujeto presupone la idea de sustancia, y la idea de substancia, a su vez, reafirma el uso tradicional de la proposición. Como lo explica Carlos Valderrama Andrade (1979), la fuerza de la proposición de desarrolla individualmente, es decir, cuando el nombre se hace sujeto en un verbo, cuando se ve reanimado por el verbo e integra una proposición: “El hombre aisladamente denota una $\cos a$;

23 Como lo explica Leonardo Tovar González (2002), la preposición es concebida por los filósofos y gramáticos como la unión del sujeto atributo o verbo; el primero tiene como función expresar una sustancia, el segundo expresa lo que dice esa sustancia. 
como sujeto del verbo, denota una persona. La proposición, pues, por el sujeto, esto es, por el nombre, en cuanto a él se refiere el verbo presupone la noción de substancia" (Caro, 1883, p. 172). Por tanto, como reflejo de las operaciones lingüísticas, el hombre es persona y substancia cuando se une al sustrato universal.

El lenguaje constituía para Caro el reflejo del orden superior y su funcionamiento, por tanto, resulta lógico que haya coincido con Jovellanos en que la mejor manera de acercar al pueblo a la tradición, sinónimo de civilización y de belleza, era a través de la enseñanza de las buenas letras y del lenguaje. En consecuencia, instruir en las leyes del lenguaje, era conectar al hombre con la esencia de la proposición, a la vez que se le acercaba a la lógica, a la retórica, a la poética $\mathrm{y}$, sobre todo, a la gramática general desde donde se formaría el juicio de los individuos: el perfeccionamiento del lenguaje garantizaría el progreso de la humanidad. Tal vez la consigna más clara de Miguel Antonio Caro era, precisamente, que las operaciones del espíritu eran inseparables de las operaciones que ordenaban el discurso, y que el arte de pensar y de hablar había llegado a ser virtualmente uno solo:

Como el hombre para pensar necesite de una colección de signos que determinen y ordenen las diferentes ideas de que sus pensamientos se componen, la lengua ha venido a ser para él un verdadero instrumento analítico y el arte de pensar ha coincidido de tal manera con el arte de hablar, que vienen ya a ser virtualmente uno mismo (Caro, 1881, p. 125).
La propuesta de Caro era, básicamente, la unión de un pensamiento religioso y científico que responde a la creencia en la creación del mundo visible por una inteligencia invisible. En este sentido, Caro pretende expresar, a través del lenguaje, la unidad en la pluralidad, esto es, el lenguaje con la peculiaridad de las lenguas dentro de la idea universal de la norma: "La unidad sin pluralidad es absolutamente estéril y carente de belleza; todas nuestras percepciones son compuestas; necesitamos conocer la unidad para concebirla y expresarla. Todo juicio, todo el lenguaje es la afirmación de la unidad" (Caro, 1881, p. 132). Precisamente el lenguaje como peculiaridad pertenece y da sustento a la unidad, le confiere el sentido del deber, la propiedad y la autoridad. Caro ve la idea de la propiedad como una derivación de la apropiación, esto significa que quien conoce la norma tendrá la apropiación de una gran parte del entendimiento: "la propiedad es derecho divino" (Caro, 1881, p. 133), un derecho que se sustenta y sustenta la tradición.

En relación con la autoridad, que surge luego de la apropiación y la aceptación de la unidad - principio que corresponde, directamente, con el plan regenerador de la unificación lingüística, religiosa y política-, y se reafirma como una propiedad primera devenida del derecho divino, que se asevera a través del conocimiento y aceptación de la norma, fundando un régimen gramatical: "régimen en gramática y gobierno en filosofía moral son en el fondo una misma idea" (Caro, 1869, p. 125). Por tanto la idea del deber, traducida en el "régimen gramatical", conforma también el sentido moral del individuo. El lenguaje con las operaciones descritas por Caro, se convierte, a su 
vez, en base de un sistema axiológico ideal, una parte ineludible y fundamental de la identidad nacional propuesta por la Regeneración. En esta dirección, la constitución propia de cada idioma fija las ideas peculiares de un pueblo que habla de sí mismo, desde sí mismo, y debe profesar respaldado por el modelo superior (Dios y latín). Estas ideas tradicionales son para Caro en cierto sentido innatas, y viven al interior del genio de la lengua, son el sustento de lo bello, y lo bello el sustento de la moral. Podríamos decir que educar a través del lenguaje y su uso resultaba para Caro un ejercicio completo, cercano a la substancia de lo universal, reflejo de las ideas principales de la Regeneración: orden, justicia y perfección, tres principios que constituían el bien y que eran el vehículo directo a Dios:

El lenguaje y su enseñanza, como todas las obras de Dios llevan en su infinita variedad el sello de la unidad en su carácter esencial, en cuanto reflejan una noción fundamental: la de lo bueno, así el hombre en el vasto campo de la invención debe reducir sus variadas obras al tipo de lo bueno, a la norma de la idea divina (Caro, 1893, p. 172).

El uso del lenguaje como obra del hombre es "bueno" y "correcto", siempre y cuando refleje las nociones del bien moral, su orden debe corresponder con la armonía de la unidad para ser bueno y cumplir con las nociones de "belleza ideal". Dicha instancia no es otra que aquella belleza que preserva $\mathrm{y}$, a su vez, pregona el orden y regenera al individuo que "desconoce" el principio divino de aquella inteligencia invisible. Al respecto, tendríamos que preguntarnos si los elementos modernizantes que pudo contener la mentalidad católica, contribuyeron en ese periodo a adoptar elementos estructurales de la racionalidad moderna, o si por el contrario, esa mentalidad fue completamente refractaria a esas innovaciones; si la substancia universal detuvo con mano contenciosa el progreso, o si por el contrario abrió más aún los ojos de aquella modernidad que se asoma tímida y cercana a la proposición.

\section{Referencias}

Arendt, H. (1998) [1958]. La condición humana. Barcelona: Paidós.

Balmes, J. (1968) [1844]. El criterio. Barcelona: Círculo de lectores.

Bello, A. (1881). Discurso pronunciado en la instalación de la Universidad de Chile. El repertorio histórico colombiano, 41, 310-311.

Caro, M. (1869). Estudio sobre el utilitarismo. Bogotá: F. Mantilla.

Caro, M. (1870). Informe sobre los elementos ideológicos de Tracy.Anales de la Universidad nacional de los Estados Unidos de Colombia, 22, 306-396.

Caro, M. (1881). Del uso en sus relaciones con el lenguaje, discurso leído ante la Academia Colombiana en la junta inaugural de 6 de Agosto de 1881. El repertorio colombiano, 38, 89-136.

Caro, M. (1893). Belleza ideal. Revista Gris, 9, 272.

Caro, M (1903) [1979]. Discursos y otras intervenciones en El Senado de la República, 1903-1904; edición, introducción y notas de Carlos Valderrama Andrade. Edición al cuidado de Guillermo Hernández Peñalosa. Bogotá: Instituto Caro y Cuervo.

Caro, M (1932). Mensaje presidencial del 20 de Julio de 1898. En Obras Completas. Tomo VI. Discursos y documentos públicos. 
Edición oficial hecha bajo la dirección de Víctor E. Caro y Antonio Gómez Restrepo. Bogotá: Imprenta Nacional, p. 244

Caro, M. (1952). Ideario hispánico. Edición dirigida por Antonio Curcio Altamar. Bogotá: Editorial Cosmos.

Caro, M. (1957). Estudios gramaticales: una advertencia y noticia bibliográfica. Bogotá: ABC.

Caro, M. (1967). Gramática de la lengua latina para el uso de los que hablan castellano. Bogotá: Foción Mantilla.

Cassirer, E (1932). La forma de pensamiento de la época de la ilustración, en Filosofía de la ilustración. México: Fondo de Cultura económica.

Castro, S. (1996). Crítica de la razón latinoamericana. Barcelona: Puvill.

Deas, M. (1993). Del poder y la Gramática. Bogotá. Tercer mundo editores.

Destutt de Tracy, A. (1871).Lógica / discurso preliminar del conde Destutt de Tracy. Traducido por el doctor Enrique Camacho; precedido de una carta del doctor José María Rojas Garrido; y seguido de un cuadro de definiciones y de contestaciones a los argumentos principales presentados contra la doctrina desarrollada en la Filosofía de la moral; escritas por el doctor Ezequiel Rojas. Bogotá: F. Mantilla.

Destutt de Tracy, A. (1822). Gramática General. Traducida por Juan Ángel Caamaño. Madrid: Imprenta de D. José del Collado.

Escobar, A. (1998) La invención del tercer mundo. Construcción y reconstrucción del Desarrollo. Bogotá: Norma.

Foucault, M. (1966). Las palabras y las cosas. Una arqueología de las ciencias humanas. México: Siglo XXI editores.

Gillis, J. (1994). Commemorations: The Politics of National Identity. New Jersey: Princeton University Press.
Galindo, S. (1956). Breve historia del tradicionalismo español. Madrid: Publicaciones Españolas.

Gordillo, A. (2000). El corazón y la norma: aproximaciones al canon conservador del siglo XIX. Bogotá: Alcaldía Mayor, p. 55

Ingarden, R. (2004). La Obrade ArteLiteraria. México: Taurus, Universidad Iberoamericana.

Jovellanos, G. (1969) [1797] Oración sobre la necesidad de unir el estudio de la Literatura al de las ciencias, en Obras en prosa. Madrid: Castalia, pp. 206-214.

Malagón, M. (2007) La Regeneración, la constitución de 1886 y el papel de la Iglesia católica. Civilizar, 11, 30-45.

Melgarejo, M. (2010). El lenguaje político de la regeneración en Colombia y México. Bogotá: Editorial Pontificia Universidad Javeriana.

Mignolo, W. (1995). The Darker Side of the Renaissance: Literacy, Territoriality, \& Colonization, 2nd Edition (Paperback).Ann Arbor: University of Michigan Press.

Montenegro, A. (2003). La Atenas Suramericana, búsqueda de los orígenes de la denominación dada a Bogotá. Memoria y Sociedad, 14, 133-143.

Müller, M (1944) [1890]. La mitología comparada: los cuentos y tradiciones populares los usos y costumbres. Buenos Aires: Assandri.

Pinzón, M. (1982). Andrés Bello Jurisconsulto. Santiago deChile: Editorial Universitaria.

Posada, E. (2003). Miguel Antonio Caro y la política colombiana. En El desafío de las ideas. Ensayos de historia intelectual y política en Colombia. Bogotá: Banco de la República, pp. 83-94.

Restrepo P, C. (comp.) (1995). Constituciones Políticas de Colombia. Bogotá: Universidad Externado de Colombia. Instituto de Estudios Constitucionales. 
Romero, J. (2001). Situaciones e Ideologías en América Latina. Medellín: Editorial Universidad de Antioquia.

Saldarriaga, O. (2004). La cuestión textos de 1870: una polémica colombiana sobre los elementos de ideología de Destutt de Tracy. En Pensar el siglo XIX. Bogotá: Instituto Pensar, Universidad Javeriana, pp. 105-164.
Tovar, L. (2002). Ciencia y fe: Miguel Antonio Caro y las ideas positivas. En Miguel Antonio Caro y la cultura de su época. Bogotá: Universidad nacional, pp. 33-55.

Valderrama, C. (1979). El pensamiento filosófico de Miguel Antonio Caro. Bogotá: Imprenta Patriótica del Instituto Caro y Cuervo, Yerbabuena.

Wills, G. (2001). San Agustín; traducción de Teófilo de Lozoya. Barcelona: Mondadori. 